taxonomy, compositions, evolution and induction heating shows is that a plausible and interesting framework exists to explain the diverse observations. Further work is obviously necessary. For example, can an asteroid actually be heated in the manner proposed? As practical experience with microwave ovens suggests, heating may take place in preferential regions, may run away owing to temperature-dependent conductivity effects, or may even short through. Furthermore, contrary to the dominant idea at present, the current distribution of asteroid types may not reflect the original distribution. The $\mathrm{S}$ and $\mathrm{M}$ types may have been injected from the region of the inner planets and the $D$ asteroids may be outer-Solar-System planetesimals (or even comets) that have migrated inward. The possibility of cometary-type orbits evolving to those resonant with Jupiter has been demonstrated theoretically ${ }^{10}$. A fundamental issue to resolve is whether the asteroid belt was a dumping ground for diverse early Solar System bodies, or whether it marks the limit of the Sun's major control over protoplanet composition and thermal evolution.

William B. McKinnon is in the Department of Earth and Planetary Sciences and McDonnell Center for the Space Sciences, Washington University, Saint Louis, Missouri 63130, USA.

1. Herbert, F. Icarus 78, 402-410 (1989)

2. Gaffey, M.J. Icarus 60, 83-114 (1984)

3. Lebofsky, L.A. \& Jones, T.D. Lunar planet. Sci. XX 562-563 (1989).

4. Prinn, R.G. \& Fegley, B. in Origin and Evolution of Plane and Satellite Atmospheres (eds Atreya, S.K., Poliack, J.B. \& Matthews. M.S.) (University of Arizona Press, Tucson, in the press)

5. Lebofsky, L.A., Jones, T.D. \& Herbert, F. in Origin and Evolution of Planet and Satellite Atmospheres (eds Atreya, S.K., Pollack, J.B. \& Matthews, M.S.) (University of Arizona Press, Tucson, in the press).

6. Duba, A.G. \& Boland, J.N. Lunar planet. Sci. XV, 232 233 (1984)

7. Duba, A.G. \& Shankland, T.J. Geophys. Res. Lett. 9 1271-1274 (1982)

8. Hutcheon, I.D., Hutchison, R. \& Wasserburg, G.J. Lunar planet. Sci XIX, 523-524 (1988)

9. Grimm, R.E. \& McSween, H.Y. Icarus (in the press)

10. Milani, A., Carpino, M., Hahn, G. \& Nobili, A.M. Icarus 78, 212-269 (1989)

\title{
Were Neanderthals the first humans to bury their dead?
}

\section{Jared M. Diamond}

THERE have been many reports that Neanderthals ritually buried their dead. Particularly striking are claims of skeletons associated with apparent remains of features such as flower offerings, burial pits, circles of goat horns and evidence of bear cults. If correctly interpreted, these graves would constitute the first evidence in human evolution not only for burial of the dead, but also for spiritual beliefs. Robert Gargett, however, concludes in a recent report that these observations do not prove the point - but there are several rebuttals accompanying his paper (Current Anthropology 30, 157-190; 1989). The debate, far from being of purely romantic interest, is central to understanding the origins of 'humanity'.

Gargett's objections to the evidence are that features attributed to intentional burial may be natural, that evidence for association of supposed grave offerings with skeletons is weak or lacking, and that interpretations of rituals go beyond the available facts. As he remarks, for example, "holes in the ground are not necessarily the result of human digging"; they can arise in many natural ways. Horizontal and vertical stones near a bear skeleton at Regourdou cave were originally interpreted as remains of a carefully constructed coffer with pavement and wells, but stones falling naturally from a cave's roof could have come to rest at these angles. Skeletons flexed as if in sleep have been taken to indicate deliberate burial, but are consistent with natural death during sleep, as is surely true of recently discovered flexed mummies of two Eskimos who had been crushed by ice falling on their house. The flowers whose pollens and anthers at Shanidar Cave have been interpreted as remains of flower offerings may have been blown into the cave's large mouth, been brought by nesting rodents, or have simply grown there. At Teshik-Tash, where a Neanderthal skeleton was described as lying within a circle of goat horns placed point down, there are actually six nearby horns of which the positions of only two suggested point-down placement. Most bones in the cave were of goats (brought by carnivores?), so that chance could explain six of the durable horns being preserved near the human skeleton.

The published responses to Gargett's article by 11 groups of authors cover the whole spectrum, from qualified agreement ("a very well founded and sound reinterpretation"; A. Weber) to scathing disapproval ("We have difficulty finding any scientific merit in this paper"; D. Frayer and A. Montet-White). Some responses concede that the older excavations discussed in detail by Gargett are inadequate, but maintain that more recent excavations are more convincing. Frayer and Montet-White, Gamble and Trinkaus identify a key problem: why are human skeletons in Europe before the last interglacial so fragmentary, and why do nearly complete skeletons not appear until the time of the Neanderthals in the last glacial?

If burial did not occur, why are some Neanderthal skeletons found with fragile elements intact, with bone frequencies as in modern cemeteries, and with anatomically natural positions, particularly as animal skeletons at similar sites of that period are not preserved in this way? Gargett responds to their question by suggesting there was better preservation of the more recent human skeletons because of the gradual natural disruption of older skeletons, and that Neanderthals, unlike animals, lived and died in caves that are favourable sites for preservation.

The contrasting views of Gargett and his critics address a wider issue. Neanderthal sites have yielded no convincing evidence of paintings, sculpture, engravings, jewellery, long-distance trade, formal bone tools, or marked geographical or temporal variation in stone tools. Nor do sites of the earliest anatomically modern Homo sapiens from southern Africa more than 100,000 years ago. All these features, as well as unquestioned burials and grave goods, appear with or soon after the arrival of anatomically modern $H$. sapiens in Europe around 35,000 years ago. Thus, anatomy that was virtually modern - at least insofar as it can be judged from skeletons - led to modern behaviour only after a long period of further development. If skeletal anatomy was not the explanation, what else caused this great leap forward in behaviour, and where and how did it suddenly arise?

Here the argument about burials becomes crucial. If Neanderthals did ritually bury their dead, they had at least one type of spiritually motivated behaviour that allies them with modern humans rather than with animals. If they did not, then perhaps they should be regarded as little more than technically skilled chimpanzees with control of fire and monotonously unvarying stone tools. In the latter case, it would be easier to understand why there is no convincing evidence for hybridization between Neanderthals and anatomically modern $H$. sapiens.

The debate between Gargett and his critics shows that these issues now merit re-investigation. Potential natural explanations for Neanderthal 'burials' should be scrutinized; animal and human skeletons likely to have become buried naturally need to be compared with intentionally buried human skeletons to provide better criteria for identifying intentional burials; and detailed accounts of St Césaire and other recent Neanderthal excavations need to be published. Until then, the question of whether Neanderthals buried their dead remains contentious.

Jared M. Diamond is a professor of Physiology at the University of California Medical School, Los Angeles, California 90024-1751, USA. 